\title{
Dentists' Annual Retention Fee to stay at current level
}

The Annual Retention Fee (ARF) for dentists is to stay at its current level of $£ 890$ for the coming year, it has been confirmed by the General Dental Council (GDC).

The move has been condemned by the British Dental Association (BDA), which said the decision showed 'cavalier disregard' for the profession and had been based on a series of claims about uncertainty and future risk.

The GDC said the ARF would remain unchanged for 2019 because it had weighed the complex picture of external risk it faced at a time when significant investment was being made for long-term improvement, and had concluded the time was not right to make the reduction it had hoped to do.

GDC Chief Executive Ian Brack said: 'As the GDC's Accounting Officer, it is my responsibility to ensure that the finances and systems of the GDC are robust and to highlight significant risks to Council.

'We have made some significant progress in terms of real improvements and efficiencies over the last few years but the combination of external risks facing the GDC for the coming year and the short-term cost of internal investment we're making to deliver Shifting the balance ${ }^{1}$ and bring further long-term savings led me to advise Council against a reduction in the ARF for the next year.'

Earlier this year, the GDC ran a consultation ${ }^{2}$ (Clear and certain: A new framework for fee-setting) on a new policy for setting fees and, in doing so, established the intention to base future consultations relating to fee-level on a three-year corporate strategy. The consultation on that strategy is due to take place in the first half of 2019.

Brack continued: 'Parliament has set the GDC very clear regulatory outcomes that we must achieve, and these focus on protecting the public and maintaining public confidence in dentistry. This will always be our first priority. We focus heavily on finding new ways to deliver our remit more cost-effectively, but we must achieve this sustainably.

'Next year we're consulting on our three-year costed corporate strategy, and the activity we propose within that will tell us what the ARF level will need to be to carry out that work.'

The BDA said the regulator had offered no detailed rationale for its decision to maintain the ARF at its current level and had shown no transparency over its process, given that the trade union believed fee levels should be debated and determined in a Council meeting open to the public, linked to a budget and business plan.

Fees remained the highest of all the UK health regulators, said the union, and continued to be used to top-up reserves, well beyond the regulator's own stated requirements.

BDA Chair Mick Armstrong said: 'The $£ 890$ ARF symbolises the GDC’s cavalier disregard for the profession it regulates, offering new excuses when the old ones have worn thin.

'We require a regulator prepared to live within its means, willing to approach upstreaming and contingency planning with a cool head. Instead we have a body that puts padding out war chests above all else.

'We have long argued that the GDC's approach to its reserves is fundamentally flawed, but even by their own measure, they now exceed their required need. The levels of uncertainty are the same for all the regulators, yet nobody else seems to be arguing in this way.

'The case for a significant fee cut remains, a coherent argument for a freeze has not been offered.'

Results of the GDC's consultation on fee setting are due this autumn.

1. General Dental Council. Shifting the balance: a better, fairer system of dental regulation. January 2018. www.gdc-uk.org/shiftingthebalance (accessed 17 July 2018).

2. General Dental Council. Consultation - Clear and certain: A new framework for fee-setting. February 2018. https://www.gdc-uk.org/api/files/Consultation-clear-and-certain.pdf (accessed 17 July 2018).

\section{Current registration fees comparison between regulators}

General Dental Council Annual Retention Fee: $£ 890$ for dentists and $£ 116$ for dental care professionals. The fee must be paid as one lump sum but can be paid by direct debit

General Medical Council Annual Retention Fee: $£ 425$ for most doctors, but there are various discounts for newly qualified doctors, refugee doctors, doctors who have been on the register for more than five years, and doctors whose income is below a specified income threshold who can have a $50 \%$ discount. Fees can be paid in monthly or quarterly instalments

Nursing and Midwifery Council Annual Registration Fee: $£ 120$ which can be paid annually or in four $£ 30$ quarterly instalments for nurses and midwives

Health and Care Professions Council Renewal Registration Fee: $£ 180$ for two years registration ( $£ 90$ annually) but newly qualified registrants receive a $50 \%$ discount for the first two years after qualifying. Payments can be made by direct debit
General Pharmaceutical Council Registration Renewal Fee: $£ 250$ for pharmacists, $£ 118$ for pharmacy technicians and $£ 241$ for registered pharmacies. Payments can be made annually or quarterly by direct debit

General Osteopathic Council Annual Registration Fee: $£ 320$ for the person's first year and then rises to $£ 430$ for their second year practising (with a reduced rate of $£ 215$ available if they are registered but not practising). The fee then rises to $£ 570$ for third year practising (with a reduced rate of $£ 320$ available). Registrants can pay their fees in a lump sum or by 10 monthly instalments by direct debit

General Optical Council Annual Registration Renewal Fee: $£ 340$. A low income fee of $£ 240$ is available for individual profession registrants whose gross personal annual income from all sources is less than $£ 12,000$. The fee must be paid in one lump sum, but can be paid by direct debit. 